\title{
GEOPROCESSAMENTO APLICADO Ȧ ANÁLISE DA FRAGILIDADE AMBIENTAL
}

\section{geoprocessing applied to environmental fragility analysis}

\author{
Elias Rodrigues da Cunha ${ }^{1}$ \\ Vitor Matheus Bacani ${ }^{2}$ \\ Lucy Ribeiro Ayach ${ }^{3}$ \\ aaCaa
}

\begin{abstract}
Resumo
O presente trabalho objetivou analisar a fragilidade ambiental da bacia hidrográfica do córrego Indaiá/MS, utilizando técnicas de geoprocessamento. Os procedimentos técnicos científicos empregados consistiram na aplicação da proposta metodológica elaborada por Ross (1994) e na adaptação da metodologia proposta por Crepani et al. (2001) com uso de Sistema de Informação Geográfica (SIG). Os resultados mostraram quatro níveis de fragilidade: baixa, média, alta e muito alta, ocupando 4,44\%, 42,10\%, 53\% e 0,31\% da área da bacia, respectivamente. Conclui-se que a bacia do córrego Indaiá apresenta um predomínio de baixo e médio grau de fragilidade potencial, entretanto quando considerado o fator antrópico tem-se um predomínio de alta fragilidade ambiental, indicando estado de alerta em relação à intensificação da ocupação, sobretudo nas áreas onde se encontram instalados os atuais assentamentos rurais.
\end{abstract}

Palavras-chave: Uso e ocupação da terra, Vulnerabilidade ambiental, Erosão, Assentamento Indaiá, Aquidauana-MS.

\begin{abstract}
The aim of this study aimed to analyze the environmental fragility analysis of a watershed Indaiá stream-MS, using geoprocessing techniques. The scientific technical procedures employed consisted in the application of the proposed methodology developed by Ross (1994) and adapting the methodology proposed by Crepani et al. (2001) using the Geographic Information System (GIS). The results showed four fragility levels: low, medium, high and very high, occupying $4.44 \%, 42.10 \%, 53 \%$ and $0.31 \%$ of the watershed area, respectively. It is concluded that of a watershed Indaiá stream presents a low prevalence and average degree of potential fragility, however when considering the anthropic factor has a high environmental fragility prevalence, indicating alertness regarding the intensification of the occupation, particularly in areas where installed the current rural settlements.
\end{abstract}

Key words: land use and occupation, environmental vulnerability, erosion, Indaiá settlement, Aquidauana-MS.

\begin{abstract}
Resumen
Este estudio tuvo como objetivo analizar la fragilidad ambiental de la cuenca de Córrego Indaiá/MS, utilizando técnicas de geoprocesamiento. Los procedimientos técnicos y científicos empleadas consistieron en la aplicación de la metodología propuesta por Ross (1994) y en la adaptación de la metodología propuesta por Crepani et al. (2001), utilizando el Sistema de Información Geográfica (SIG). Los resultados mostraron cuatro niveles de fragilidad: baja, media, alta y muy alta, ocupando 4,44\%, 42,10\%,53\% y el 0,31\% de la superficie de la cuenca, respectivamente. Se concluye que la cuenca del Córrego Indaiá presenta una prevalencia de grado bajo y medio de debilidad ambiental. Sin embargo, cuando se considera el factor antrópico tiene una prevalencia de alto grado en la fragilidad ambiental, lo que indica el estado de alerta con la intensificación de la ocupación, sobre todo en áreas en las que instalan los asentamientos rurales actuales.
\end{abstract}

Mots clés: Hygiéniste, Épidémies, Pratiques urbaines.

(1) Mestrando em Geografia pela Universidade Federal do Mato Grosso do Sul- Rua Oscar Trindade de Barros, ${ }^{\circ}$ 740, CEP: 79200-000, Aquidauana (MS), Brasil. Tel (+55 67) 32410400 - eliasrodriguesdacunha@hotmail.com

(2) Prof. Dr. da Universidade Federal de Mato Grosso do Sul - Rua Oscar Trindade de Barros, n 740, CEP: 79200-000, Aquidauana (MS), Brasil. Tel (+55 67) 32410400 - vitor.bacani@ufms.br

(3) $\operatorname{Prof}^{\mathrm{a}} \operatorname{Dr}^{\mathrm{a}}$ da Universidade Federal de Mato Grosso do Sul - Rua Oscar Trindade de Barros, $\mathrm{n}^{\mathrm{o}}$ 740, CEP: 79200-000, Aquidauana (MS), Brasil. Tel (+55 67) 32410400 - luayach@terra.com.br

$$
\text { aaCaa }
$$




\section{INTRODUÇÃO}

O processo de uso e ocupação inadequado associado à falta de práticas de planejamento ambiental e conservação do solo promove o aumento da velocidade do escoamento superficial das águas pluviais, carregamento de sedimentos à jusante, perda de nutrientes, entre outros fatores que favorecem o quadro de degradação ambiental em bacias hidrográficas, comprometendo a qualidade desse ambiente devido sua característica sistêmica (fluxo constante de matéria e energia).

Neste sentido, estudos ambientais em bacia hidrográfica são fundamentais para o entendimento dos processos que ocorrem nessas unidades, tendo como objetivo o uso racional e a preservação dos recursos naturais. O conhecimento das potencialidades e limitações de uso e ocupação passa primeiramente pelo levantamento de seus atributos físicos, tais como: relevo, geologia, geomorfologia, clima, solo, vegetação e hidrografia, por meio da análise da fragilidade potencial e ambiental (ROSS, 1994).

A fragilidade ambiental é o grau de susceptibilidade a qualquer tipo de dano, ou seja, esta relacionada aos ambientes em situação de risco, causada pelas próprias condições naturais somadas às contribuições das ações antrópicas, provocadas pelo uso e ocupação da terra (SPÖRL, 2007; BATISTA e SILVA, 2013). Segundo Santos (2005), a fragilidade potencial se caracteriza pela fragilidade natural a que uma determinada área está submetida, ou seja, a partir do tipo de solo, declividade do relevo, índice de pluviosidade, entre outros, que este local poderá ou não apresentar um equilíbrio natural [...]. Sendo assim, ao se analisar determinadas áreas sobre o prisma da fragilidade potencial, se consideram apenas os aspectos naturais.

O conhecimento dos níveis de fragilidades presentes em uma bacia hidrográfica, por meio da integração de diversas variáveis que interferem nas potencialidades dos recursos naturais, possibilita compreender a realidade e obter uma visão sobre quais são as opções mais adequadas para o uso da terra (SPÖRL, 2001).

Com o passar do tempo, a adoção de bacia hidrográfica como unidade de planejamento amplia-se para aplicações diversas, marcadas notadamente pelos avanços tecnológicos. O uso das geotecnologias como ferramenta de análise das bacias hidrográficas, possibilita a realização de uma efetiva radiografia desses sistemas ambientais, a partir da elaboração de modelos digitais, implementados em um Sistema de Informação Geográfica (SIG), (BACANI, 2010).

O uso e ocupação da terra na bacia hidrográfica do córrego Indaiá têm passado por uma expressiva transformação em função da instalação do primeiro complexo de assentamento rural do município de Aquidauana- MS. Em 15 de dezembro de 2009, o Instituto Nacional de Colonização e Reforma Agrária (INCRA) realizou o lançamento simultâneo dos quatro primeiros projetos de reforma agrária em Aquidauana- MS (INCRA, 2009). Estudos de planejamento e gestão ambiental ainda não foram realizados na área. Tal fato acentua a importância da realização de pesquisa para analisar a fragilidade (deste ambiente) natural que se depara com uma expressiva pressão antrópica.

O processo de ocupação desencadeado pela implantação dos Assentamentos na bacia do córrego Indaiá exige a análise dos impactos diretos e indiretos no sistema ambiental. Portanto, torna-se fundamental analisar a fragilidade ambiental da bacia hidrográfica do córrego Indaiá, a partir de técnicas de Geoprocessamento, como forma de contribuição diante das intervenções humanas na bacia.

\section{ÁREA DE ESTUDO}

A bacia hidrográfica do córrego Indaiá, com área de $94,63 \mathrm{~km}^{2}$, está localizada entre as lati-

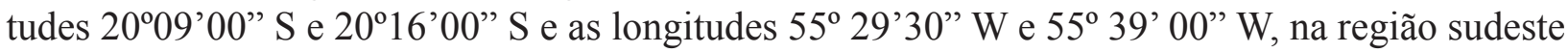
do município de Aquidauana, no estado de Mato Grosso do Sul (Figura 1). O córrego Indaiá está inserido na Bacia do Alto Rio Paraguai (BAP), é afluente do rio Taboco, que por consequência adentra a Planície Pantaneira.

A bacia hidrográfica do córrego Indaiá está inserida no Bioma Cerrado, a vegetação predominante é a Savana Arbórea Densa (Cerradão) e destaca-se a presença de Agropecuária e Pastagem 
(BRASIL, 1982). Do ponto de vista geomorfológico, a área da bacia está inserida em duas macrounidades morfoestruturais: a Bacia Sedimentar do Paraná e a Bacia Hidrográfica do Rio Paraguai, subdivididas nas unidades morfoesculturais, Planalto Maracaju-Campo Grande e Depressão do Paraguai (BRASIL, 1982). As formas de relevo dominantes são colinas convexas com declividades que variam de 6 a 20\%, além da presença de planície fluvial, morros e morrotes (CUNHA et al. 2013).

A Geologia é composta pelas seguintes formações: formação furnas (grupo Paraná), formação Aquidauana e por Aluviões fluviais (BRASIL, 1982). De acordo com levantamento em trabalho de campo e o Plano de Conservação da Bacia do Alto Paraguai- PCBAP (BRASIL, 1997) os solos predominantes na área investigada são: Gleissolos tiomórficos de textura arenosa, localizados em toda a planície fluvial; Neossolos quartzarênicos de textura arenosa que predominam em mais da metade da área da bacia, faixa que vai desde algumas de suas nascentes (na margem esquerda) até a proximidade de sua foz com rio Taboco; Latossolos vermelhos álicos de textura franco-arenosa, encontrados ao longo de alguns dos seus tributários (na margem direita), ambos limitados com a planície fluvial e Neossolos litólicos de textura indiscriminada encontrados nos morros e morrotes.

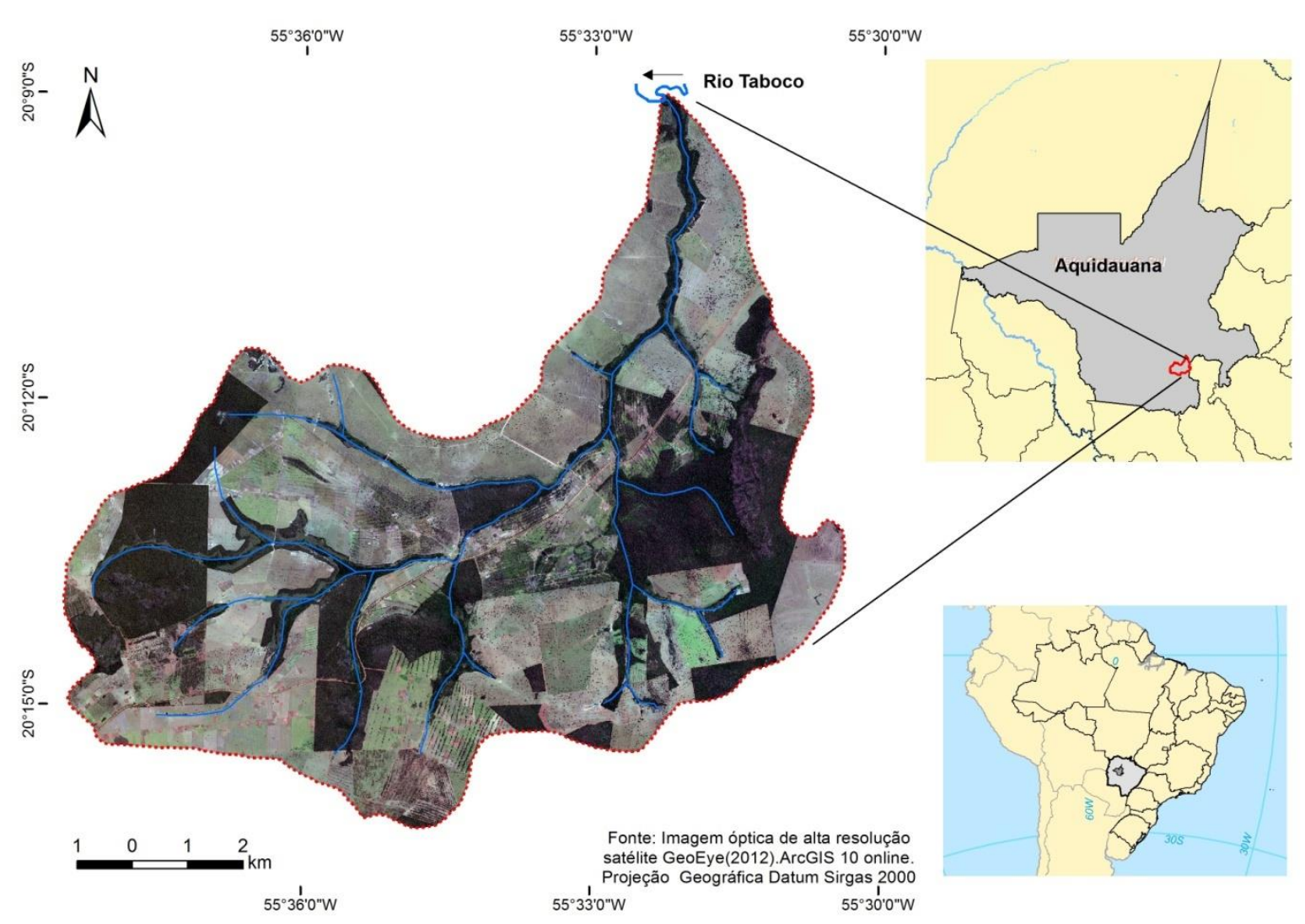

Figura1 - Localização da bacia hidrográfica do córrego Indaiá-MS

Na região onde está inserida a unidade hidrográfica estudada apresenta precipitação média anual em torno de 1350 mm (SANT'ANNA NETTO, 1993). Geralmente a média térmica da região é alta, ficando em torno de $25^{\circ} \mathrm{C}$, ao passo que a média mensal do mês mais quente (janeiro) alcança $27,5^{\circ} \mathrm{C}$ e a do mês mais frio (junho) atinge $22,5^{\circ} \mathrm{C}$. Entretanto, são comuns na região temperaturas máximas superiores a $40^{\circ} \mathrm{C}$ nos meses de verão e nos meses de inverno, temperaturas mínimas inferiores a $5^{\circ} \mathrm{C}$ (PINTO, 1998). 


\section{METODOLOGIA}

\section{DELIMITAÇÃO DA BACIA HIDROGRÁFICA E EXTRAÇÃO DA REDE DE DRENAGEM}

A delimitação da bacia hidrográfica do córrego Indaiá consistiu na aplicação metodológica elaborada por Fitz (2008). Utilizou-se a carta topográfica Folha Aquidauana (SF. 21- X-A III), na escala de 1:100.000 (BRASIL, 1972) que foi digitalizada em scanner de mesa e Modelo Digital de Elevação (MDE) derivados da Shuttle Radar Topography Mission (SRTM) e interpoladas pelo método da krigagem com resolução espacial de $\approx 30 \mathrm{~m}$ (VALERIANO, 2008). Através do processamento do MDE em ambiente SIG foram geradas curvas de nível, com equidistâncias de 15m que auxiliaram na delimitação e extração da rede de drenagem mais detalhada.

\section{DECLIVIDADE}

A modelagem numérica de terreno foi realizada com base no Modelo de Grade Regular Retangular (MGRR), segundo procedimentos descritos em Câmara et al. (2007). Extraiu um Modelo Tridimensional do Relevo, que deu origem ao mapa clinográfico na escala de 1:60.000, segundo intervalos estabelecidos por Ross (1994).

\section{SOLOS}

As unidades de solos da bacia hidrográfica do córrego Indaiá foram delimitadas na escala de 1:60.000. Inicialmente por fotointerpretação de imagem de satélite Landsat 5 órbita 225, ponto 74 e fotografias aéreas, na escala de 1:60.000 (USAF, 1966), apoiando-se na observação das quebras de relevo e na rede de drenagem identificou-se as unidades fisiográficas da paisagem.

Em seguida, realizou-se amostragem de solos nas unidades fisiográficas da paisagem, cujo procedimento metodológico empregado foi o apresentado no manual de descrição e coleta de solo no campo, descrito em Santos et al. (2005). Foram coletadas amostras em campo através de tradagens, em seguida foram analisadas as características morfológicas tais como: cor, textura, além da observação da disposição dos horizontes pedogenéticos e diagnósticos. Da interação destas informações gerou-se o mapa de solos da bacia, também na escala de 1.60.000.

Intensidade pluviométrica

O mapa de variabilidade espacial pluviométrica foi elaborado em ambiente ArcMap 10 (ESRI, 2010) a partir de médias anuais pluviométricas do período de 1970 a 2007 de 3 estações pluviométricas da Agência Nacional das Águas (ANA), sendo duas localizadas no município de Aquidauana, quais sejam: nos distritos de Cipolândia (S 2007'37', W 55²3'34') e fazenda Taboco (S $20^{\circ} 04^{\prime} 13^{\prime}$, W $\left.55^{\circ} 38^{\prime} 39^{\prime \prime}\right)$, e a outra no município de Dois Irmãos do Buriti, na fazenda Lajeado (S 2017'29"'W 55²6’41').

Para representação espacial pluviométrica da região onde se localiza a bacia hidrográfica do córrego Indaiá, empregou-se o método de interpolação, denominado Inverso do Quadrado da Distância (IQD) ou The Inverse Distance Weighted (IDW).

Através da relação entre a precipitação média anual (PMA) e duração do período chuvoso (DPC) foi obtida a intensidade pluviométrica (IP), apresentada na equação 1 (CREPANI et al., 2001).

As intensidades pluviométricas encontradas para bacia hidrográfica a partir dos dados interpolados das estações meteorológicas e a aplicação da equação 1 foram: 138,7mm; 140,5mm; 142,3mm; $144,2 \mathrm{~mm} ; 146,0 \mathrm{~mm}$ e $147,9 \mathrm{~mm}$.

Eq. 1

$$
\mathrm{IP}=\frac{\mathrm{PMA}}{\mathrm{DPC}}
$$


A partir dos valores obtidos de intensidade pluviométrica e sua relação com a vulnerabilidade à perda de solo da bacia hidrográfica do córrego Indaiá elaborou-se uma adaptação metodológica com base numa regra de três simples (Relação 1) entre os valores máximo de vulnerabilidade à perda de solo (CREPANI et al., 2001) e o grau de fragilidade definido por Ross (1994).

Relação 1.

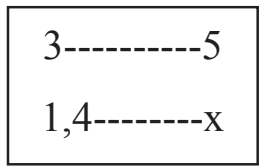

Sendo:

\begin{tabular}{|l|l|l|c|}
\hline CREPANI et al. (2001) & Valores & ROSS (1994) & Valores \\
\hline Muito Alta vulnerabilidade à perda de solo & $\mathbf{3}$ & Muito Alta fragilidade & $\mathbf{5}$ \\
\hline Vulnerabilidade da área de estudo & & & $\mathbf{X}$ \\
\hline
\end{tabular}

\section{GEOMORFOLOGIA (PLANÍCIE FLUVIAL)}

A compartimentação geomorfológica foi elaborada a partir de procedimentos técnicos científicos descritos por Ross (1992), Florenzano (2008), manual técnico de geomorfologia (IBGE, 2009) e Novo (2008). O mapeamento geomorfológico, bem como a delimitação da planície fluvial utilizada no mapeamento da fragilidade potencial foram elaborados a partir de produtos cartográficos intermediários derivados de análises fisiográficas (imagens dos satélites LANDSAT 5 TM e GeoEye) e morfométricas apoiadas em MDE. Toda elaboração da cartografia digital teve como ambiente de trabalho ArcMap 10 (ESRI, 2010).

\section{USO DA TERRA E COBERTURA VEGETAL}

O mapeamento de uso da terra e cobertura vegetal foi elaborado de acordo com a metodologia de interpretação digital de imagem proposta por Florenzano (2008) e Novo (2010), enquanto que o padrão de cores adotado foi aplicado segundo o Manual de Uso de Ocupação da Terra do IBGE (2013). Para a elaboração do mapeamento utilizou-se imagem LANDSAT-5/TM, orbita 225, ponto 74, composição colorida 3B4G5R de 22/09/2011, e, com uso do software SPRING 5.1.8 (CÂMARA et al., 1996) foram percorridas as seguintes etapas:

Pré-processamento: para o georreferenciamento da imagem LANDSAT-5 TM, composição colorida 3B4G5R de 22/09/2011, utilizou-se pontos de controle obtidos de uma imagem de satélite LANDSAT-5 TM, composição colorida 3B4G5R de 09/11/1988, disponível no endereço http://glcf. umiacs.umd.edu/.

Técnica de Realce: a finalidade da técnica de realce foi melhorar a qualidade visual das imagens e facilitar o trabalho de interpretação. A técnica empregada foi de ampliação de contraste linear.

Técnica de Segmentação: procedimento computacional aplicado antes de um algoritmo de classificação. A segmentação permitiu dividir a imagem em regiões espectralmente homogêneas. Na aplicação da segmentação foram definidos dois limiares: limiar de similaridade, o qual duas regiões são consideradas similares e agrupadas em uma única região e o limiar de área, que representa o número de pixels, para que uma região seja individualizada. A partir da segmentação da imagem com limiares 08 e 06, foi possível definir áreas amostrais para o treinamento.

Extração de regiões: foram extraídos alguns parâmetros dos polígonos, como: posicionamento, média de níveis de cinza e matriz de covariância para serem utilizados na classificação.

Técnica de Classificação por Regiões (Battacharya): a etapa de classificação consiste em identificar as regiões e rotular, como uma classe. Para o mapeamento de uso da terra e cobertura 
vegetal da bacia hidrográfica do córrego Indaiá- MS utilizou-se o classificador Bhattacharya, que emprega as amostras de treinamento para estimar a função de densidade de probabilidade das classes apontadas no treinamento (MOREIRA, 2005). Em todas as áreas foram selecionadas amostras de treinamento, considerando, as classes de interesse, as quais foram definidas 5 classes amostrais: Mata, Mata queimada, Mata queimada em regeneração, Pastagem e Solo Exposto, na qual cada grupo de pixels (regiões) da imagem foi classificado em uma das classes definidas.

\section{LEGISLAÇÃO AMBIENTAL}

O mapa de legislação ambiental foi elaborado com base no Código Florestal Brasileiro lei $\mathrm{n}^{\mathrm{o}}$ 12.651 de 25 de maio de 2012 (BRASIL, 2012). As áreas de APPs (Áreas de Preservação Permanentes) foram delimitadas a partir de uma ferramenta buffer (ou distância) em que SIG que gera a partir da entrada de um vetor (linha, ponto ou polígono) uma zona de influência em torno das geometrias dos elementos vetoriais de um layer de entrada, no caso representado pelas drenagens (linhas) e nascentes (pontos), distâncias de 30 e 50 metros, respectivamente. Os vetores das Áreas de Reserva Legal e Áreas de Reserva Remanescentes (Remanescentes Florestais) foram extraídos da Planta Geral do Projeto de Assentamentos Indaiá.

\section{FRAGILIDADE POTENCIAL E AMBIENTAL}

Os procedimentos técnicos científicos empregados consistiram na aplicação da proposta metodológica descrita por Ross (1994) e Crepani et al. (2001). Para a elaboração do mapa síntese de fragilidade ambiental foram aplicados os métodos de álgebra de campo e sobreposição ponderada, disponível no ArcMap 10 (ESRI, 2010).

94 Inicialmente foi feita a conversão dos dados vetoriais em formato matricial (formato Grid.) e posteriormente a reclassificação por meio da ferramenta Spatial Analyst/Reclassify. Na sequência foram combinados pelo método de sobreposição ponderada os dados de declividade, intensidade pluviométrica, solos e sobreposição do geomorfológico (planície fluvial) que resultou na fragilidade potencial e fragilidade natural à inundação. Para a elaboração do mapa de fragilidade ambiental (fragilidade emergente) foram combinados os dados de fragilidade potencial e uso da terra e cobertura vegetal. As etapas percorridas para geração de ambos os mapas foram as seguintes: Spatial Analyst Tolls/Overlay/Weighted Overlay.

\section{RESULTADOS E DISCUSSÃO}

\section{CLINOGRAFIA}

A Tabela 1 apresenta as classes mapeadas, quantificação e níveis de fragilidade das declividades. Na bacia hidrográfica do córrego Indaiá foi possível identificar em $61 \%$ do total de sua área o predomínio de inclinações que variam entre 0 a $6 \%$, cujo grau de fragilidade é muito baixo associadas a relevos com formas praticamente planas localizadas desde as nascentes até a sua foz (Tabela 1).

Tabela 1- Classes de declividade, quantificação e níveis de Fragilid
\begin{tabular}{|l|c|l|}
\hline Classes de declividade & Km $^{2}$ & *Níveis de Fragilidade \\
\hline $0 \%$ a $6 \%$ & 58,54 & 1-(Muito Baixa) \\
\hline $6 \%$ a $12 \%$ & 33,82 & 2-(Baixa) \\
$12 \%$ a $20 \%$ & & 3- (Média) \\
\hline $12 \%$ a $20 \%$ & 1,74 & 3- (Média) \\
\hline $20 \%$ a $30 \%$ & 0,29 & 4- (Alta) \\
\hline Acima de $30 \%$ & 0,24 & 5- (Muito Alta) \\
\hline Total & 94,63 & \\
\hline
\end{tabular}

Fonte: *Adaptado de Ross (1994). 
A segunda classe, destaca-se declividades de $6 \%$ a $12 \%$ classificada como de baixa fragilidade, ocupando um total de 36\%, que estende-se ao longo de toda bacia. Em seguida, ocorrem as inclinições de média fragilidade de $12 \%$ a $20 \%$, que representam $0,2 \%$ e são encontradas em três áreas: a montante nas proximidades de duas nascentes, ao longo do médio curso na margem direita e à jusante (margem direita) nas aproximidades de três nascentes dos seus tribútarios.

As fortes declividades $20 \%$ a $30 \%$, estão localizadas na sequência das inclinações de $12 \%$ a $20 \%$ associadas a relevo ondulado que correspondem a $0,6 \%$ da área total da bacia. As inclinações maiores de $30 \%$, de muito alta fragilidade compreendem $0,4 \%$ da bacia e ocorrem a oeste, nas áreas onde o relevo apresenta formas fortemente onduladas, caracterizadas pela presença de morrote e morro.

No que tange ao predomínio das baixas declividades, resultados semelhantes na bacia do ribeirão Água Grande foram observados por Petsch et al. (2012) evidenciando que tal fato não contribuiu para atenuar a fragilidade ambiental. Segundo Gogo et al. (2003) o aumento da declividade é um dos fatores que influência fortemente nos processos de erosão, sobretudo na erosão hídrica do solo, pois, à medida que ela aumenta, aumentam o volume e a velocidade da enxurrada e diminui a infiltração de água no solo.

\section{SOLOS}

Dentre as unidades de solos destacam-se na bacia os Neossolos Quartzarênico de textura arenosa ocorrem em mais da metade de sua extensão territorial, ocupando 52,75\% (Tabela 2). Ocorre desde as nascentes até a foz com o rio Taboco, onde se desenvolve sobre um relevo suave ondulado composto, predominantemente, por colinas convexas, unidade que se sustenta sobre a litologia da Formação Furnas caracterizada pela presença de arenitos quartzosos, grosseiro, tendo intercaladas camadas de arenito extremamente micáceo, apresentando frequentemente estratificação cruzada. São solos quimicamente pobres, e com alta taxa de infiltração, devido à sua composição mineralógica. Nesse contexto, do ponto de vista pedológico houve um predomínio de muito alta fragilidade. Em estudo feito por Scopel et al. (2013) observou-se o desenvolvimento de processos erosivos em solos arenosos numa situação de declividade de $3 \%$, o que mostra a alta susceptibilidade a erosão mesmo em relevo suave ondulado.

Tabela 2 - Tipos de solos e quantificação de área e níveis de fragilidades

\begin{tabular}{|l|l|l|}
\hline Tipos de Solos & $\mathrm{Km}^{2}$ & *Níveis de fragilidade \\
\hline Neossolos Quartzarênicos tex. arenosa & 49,93 & 5- (Muito Alta) \\
\hline Latossolos Vermelhos álicos tex. franco-arenosa & 31,67 & 1- Baixa \\
\hline Gleissolos Tiomórficos tex. Arenosa & & \\
\hline Neossolos Litólicos tex. indiscriminada & 10,63 & 4- (Alta) \\
\hline Total & 2,40 & 5- (Muito Alta) \\
\hline
\end{tabular}

Fonte: *Adaptado de Ross (1994).

Os Latossolos Vermelhos álicos são encontrados em 33,46\% da área total da bacia (Tabela 2), apresentam características litológicas da Formação Aquidauana, composta por siltitos arenosos e arenitos finos a médios e até grosseiros, mineralogicamente nos níveis grosseiros, predominam grãos de quartzo com alguns raros feldspatos caolinizados. Ocupam unidades geomorfológicas de formas suaves onduladas dominadas por colinas convexas. Os latossolos são muito intemperizados, apresenta baixa retenção a umidade, pequena reserva de nutrientes para as plantas, representados 
normalmente por sua baixa à média capacidade de troca de cátions (BRASIL, 1982). Devido suas características são classificados como de baixa fragilidade. Os Gleissolos, texturalmente arenosos, ocupam $11,25 \%$ da área de estudo (Tabela 2) e são encontrados ao longo da planície fluvial, associados a um relevo plano. Suas características são influenciadas pela contribuição de partículas provenientes dos solos das posições mais altas e da água de drenagem, uma vez que são formados em áreas de recepção ou trânsito de produtos transportados. Diferentemente dos Latossolos, estes possuem alta fragilidade.

Neossolos Litólicos são solos pouco desenvolvidos, compreendem a menor unidade de solos da bacia, ocupando aproximadamente $2,54 \%$ da área. São encontrados nos topos de morro e morrote convexos no extremo oeste da bacia. Desenvolvem-se sobre um relevo fortemente ondulado, apresentam alto nível de fragilidade decorrente do declive acentuado que ultrapassam os $30 \%$, pouca espessura (soma dos horizontes não ultrapassam $50 \mathrm{~cm}$ ) e pela dificuldade de infiltração da água no perfil do solo, fatores que retardam o desenvolvimento pedogenético e, por isso são classificados como de muito alta fragilidade.

\section{USO DA TERRA E COBERTURA VEGETAL}

Historicamente a bacia foi predominantemente ocupada pela pecuária extensiva, atualmente, o uso da terra na área passa por uma expressiva transformação em função da instalação do primeiro complexo de assentamento rural do município de Aquidauana- MS. Precisamente em 15 de dezembro de 2009, o INCRA (Instituto Nacional de Colonização e Reforma Agrária) realizou o lançamento simultâneo dos quatro primeiros projetos de reforma agrária Assentamento Indaiá I, II, III e IV em Aquidauana- MS, alterando significativamente a configuração da paisagem local (CUNHA et al., 2012) (Figura 2).

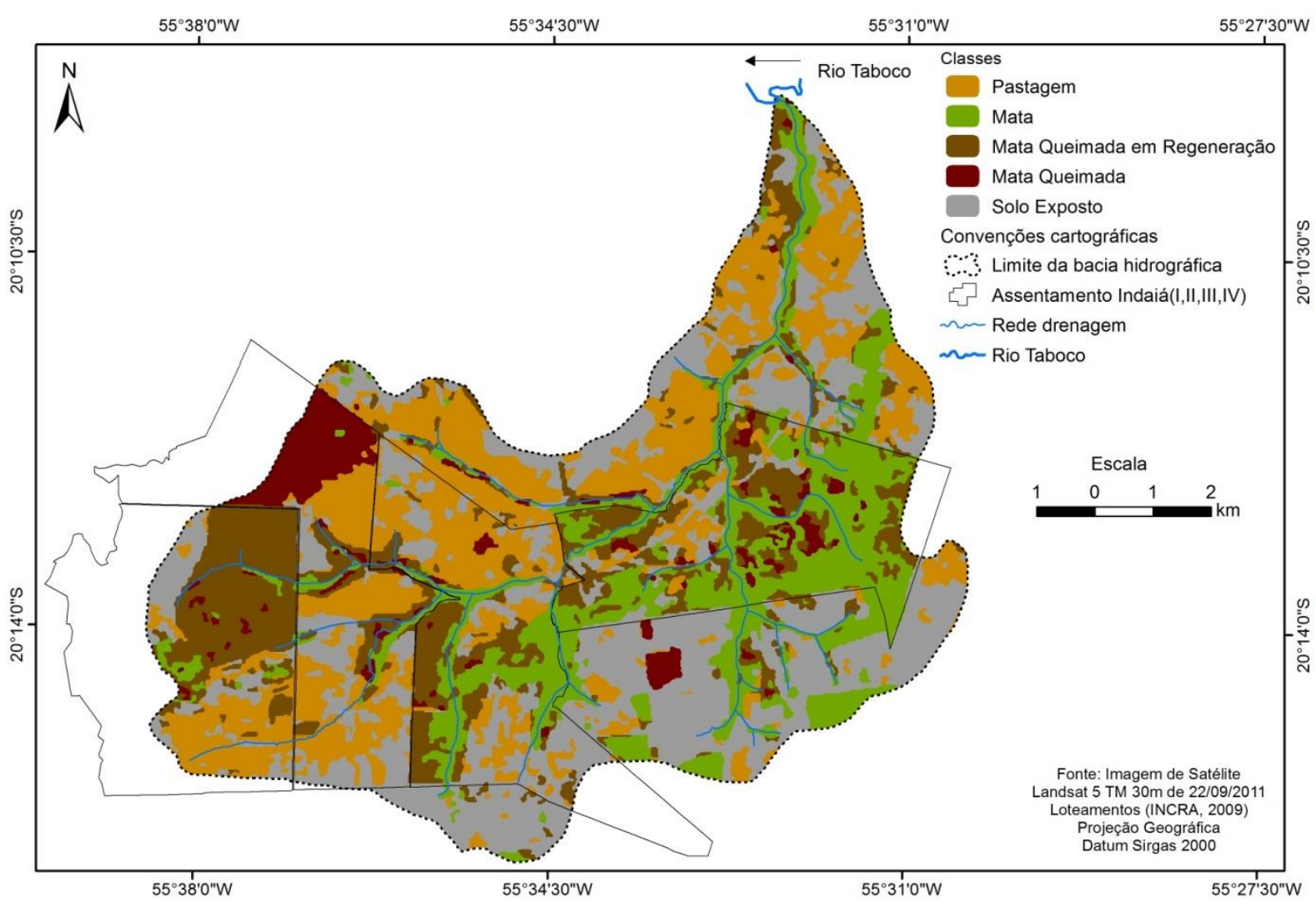

Figura 2 - Uso da terra e cobertura vegetal da bacia hidrográfica do córrego Indaiá- MS. 
As classes de uso da terra e cobertura vegetal da bacia hidrográfica do córrego Indaiá mapeadas foram: (A) Pastagem, (B) Mata, (C) Mata Queimada, (D) Mata Queimada em Regeneração, (E) Solo Exposto (Tabela 3).

A) Pastagem: corresponde 26, 66\% da área total da bacia, cujo grau de proteção à erosão pode variar em função do tipo de manejo das pastagens. Configuram-se como de média proteção a pastagem recuperada e/ou em bom estado de manutenção (pastagens com baixo grau de pisoteio), que se desenvolvem sobre relevo suave ondulado, localizada na margem esquerda do canal principal, mais precisamente na fazenda Rancho Grande, propriedade que tem como atividade econômica a pecuária.

Outro grau de proteção é a baixa, relacionada com a pastagem que sofre processo de degradação, caracterizado segundo Macedo (2000) como ação evolutiva de perda de vigor e produtividade forrageira, sem possibilidade de recuperação natural, que afeta a produção e o desempenho animal e culmina com a degradação do solo e dos recursos naturais em função de manejos inadequados. Causada por diversos fatores, dentre eles, má escolha da espécie forrageira, má formação inicial, falta de adubação de manutenção e manejo da pastagem inadequado. Esse tipo de pastagem é encontrado no sudoeste da bacia, nas áreas relativas à antiga fazenda Indaiá que atualmente se destina a instalação de parte do complexo de assentamentos (Tabela 3).

Tabela 3 - Uso da terra e cobertura vegetal e níveis de fragilidade da bacia hidrográfica do córrego Indaiá- MS

\begin{tabular}{|l|l|l|}
\hline Classes & $\mathbf{k m}^{\mathbf{2}}$ & *Níveis de Fragilidade \\
\hline Pastagem & 25,34 & 3- (Média) \\
\hline Mata & 18,78 & 2-(Baixa) \\
\hline Mata Queimada & & 3- (Alta) \\
\hline Mata Queimada em Regeneração & 17,14 & 5- (Muito Alta) \\
\hline $\begin{array}{l}\text { Solo Exposto } \\
\text { Total }\end{array}$ & $\mathbf{2 8 , 7 6}$ & 5- (Muito Alta) \\
\hline
\end{tabular}

Fonte: *Adaptado de Ross (1994).

Ocorre a introdução da pastagem ao longo das margens do córrego Água Limpa (tributário do córrego Indaiá), áreas que deveriam ser ocupadas por formações vegetais caracterizadas por matas ciliares, que segundo o Código Florestal Brasileiro (BRASIL, 2012) é associada como Área de Preservação Permanente (APP), caracterizada coberta ou não por vegetação nativa com a função ambiental de preservar os recursos hídricos, a paisagem, a estabilidade geológica e a biodiversidade, facilitar o fluxo gênico da fauna e flora, proteger o solo e assegurar o bem estar das populações humanas. As matas ciliares atuam como barreira física, regulando os processos de troca entre os ecossistemas terrestres e aquáticos e desenvolvendo condições propícias à infiltração (KAGEYAMA, 1986; LIMA, 1989). Sua ausência ao longo das margens aumenta a possibilidade de contaminação dos cursos d'água por sedimentos, favorecendo processos erosivos nas margens e assoreamento do leito do córrego.

B) Mata: relacionada à presença de vegetação do tipo Savana Arbórea Densa (Cerradão) compreende aproximadamente $19,84 \%$ da área total da bacia, encontram- se em pequenas faixas ao longo das drenagens e com mais expressividade em duas porções definidas no mapa de loteamento segundo INCRA (BRASIL, 2009) como áreas de Reserva Legal, as mesmas espacializadas na região central e leste da bacia. Predomina formas de relevo onduladas caracterizadas por colinas convexas com declividades até $20 \%$. 
A cobertura vegetal dessas áreas tem uma importante função de estabilização dessas vertentes, seguindo esse pressuposto Bertoni (2008) atribui cobertura vegetal como a defesa de um terreno contra a erosão, tal efeito da cobertura vegetal pode ser assim enumerado: 1) proteção direta contra o impacto das gotas das chuvas, 2) dispersão da água, interceptando-a e evaporando-a antes que atinja o solo, 3) decomposição das raízes das plantas que, formando canalículos no solo, aumentam a infiltração da água, 4) melhoramento da estrutura do solo pela adição de matéria orgânica, aumentando assim a sua capacidade de retenção de água e 5) diminuição da velocidade de escoamento da enxurrada pelo aumento do atrito na superfície.

C) Mata Queimada: classificada como de muito alta fragilidade abrange menos de 5\% da área total, encontra-se ao longo de toda bacia, com maior expressividade a noroeste da bacia, caracterizada pela presença de formação vegetal do tipo Cerradão, área que foi destinada como Reserva Remanescente, segundo INCRA(BRASIL, 2009). As principais causas dos incêndios nessas áreas são de responsabilidade dos pequenos agricultores dos assentamentos, pois utilizam o fogo como prática para limpeza da área e preparo para fins agrícolas.

O uso dessa prática, geralmente de forma inadequada causa a queima de áreas muito maiores do que o necessário devido à perda do controle da mesma. Fato comprovado em setembro de 2010, na qual dois assentados foram autuados por crime ambiental e receberam cada um multa de R\$ 10 mil por terem queimado um terreno para limpeza. De acordo com a Polícia Militar Ambiental o fogo acabou saindo do controle dos assentados e queimou uma área de 10 hectares.

Segundo Garzotti (2007) a queimada elimina a cobertura vegetal do solo favorecendo o escoamento superficial da água das chuvas, agravando o processo erosivo. Esse fenômeno é explicado pela insuficiência de cobertura do solo superficial que sofre forte compactação pelas chuvas e vai ficando impermeável, dificultando a infiltração da água e a brota da vegetação. $\mathrm{O}$ solo vai empobrecendo, pela eliminação da matéria orgânica. A queima altera a umidade do solo, por causa das mudanças na taxa de infiltração de água, no volume de enxurrada, na taxa de transpiração, na porosidade e na repelência do solo à água e, conforme suas características, o solo pode ficar mais impermeável, situação esta que torna o terreno excessivamente duro e mais sujeito a erosões.

(D) Mata Queimada em Regeneração: distribuída em 18,11\% da área de estudo, encontram-se ao longo de toda bacia, porém, a oeste ocorre com maior expressividade em duas grandes áreas definidas como áreas de Reserva Legal e Reserva Remanescente, além da porção central numa área destinada a Reserva Remanescente (Remanescentes Florestais), ambas de vegetação do tipo Cerradão.

(E) Solo Exposto: maior área mapeada corresponde a 30,4\% da área de estudo, caracterizada principalmente pela antiga presença de pastagem. Encontra- se principalmente ao longo das estradas e nas regiões onde localiza o complexo de assentamentos Indaiá. A partir de trabalho de campo, pode-se verificar que as áreas de solo expostos nos assentamentos se deu em virtude da intensificação da retirada da cobertura vegetal para introdução de culturas agrícolas de subsistência.

\section{LEGISLAÇÃO AMBIENTAL}

Toda a drenagem da bacia hidrográfica do córrego Indaiá tem largura inferior a 10 metros, todavia as APPs ao longo dos canais apresentaram largura de 30 metros a partir da borda da calha do leito. Foram identificadas 17 nascentes a partir dos pontos foram gerados raios de 50 metros referentes à faixa de proteção das APPs.

As APPs mapeadas como topo de morro estão associadas à presença de forma de relevo convexa e solo em processo de formação, caracterizados como de alta erodibilidade. As áreas de Reserva 
Legal e Reserva Remanescente encontram-se ao longo da bacia em áreas de vegetação natural definidas pelo INCRA (BRASIL, 2009), quando se instalou o complexo de assentamento Indaiá.

A partir da espacialização das áreas de proteção (Figura 3) foi possível verificar que as disposições definidas pelo novo Código Florestal Brasileiro (BRASIL, 2012), não estão sendo cumpridas, haja vista que as essas áreas restritas a uso e ocupação estão sendo modificadas decorrentes de ações antrópicas, tais como:

- Desmatamentos das margens do córrego Indaiá e seus tributários;

- Represamentos e captação de água em diversos pontos do córrego Água Limpa;

- Desmatamento e queima da vegetação natural das áreas de Reserva Legal e Reserva Remanescente;

- Desmatamento da vegetação natural no entorno das nascentes.

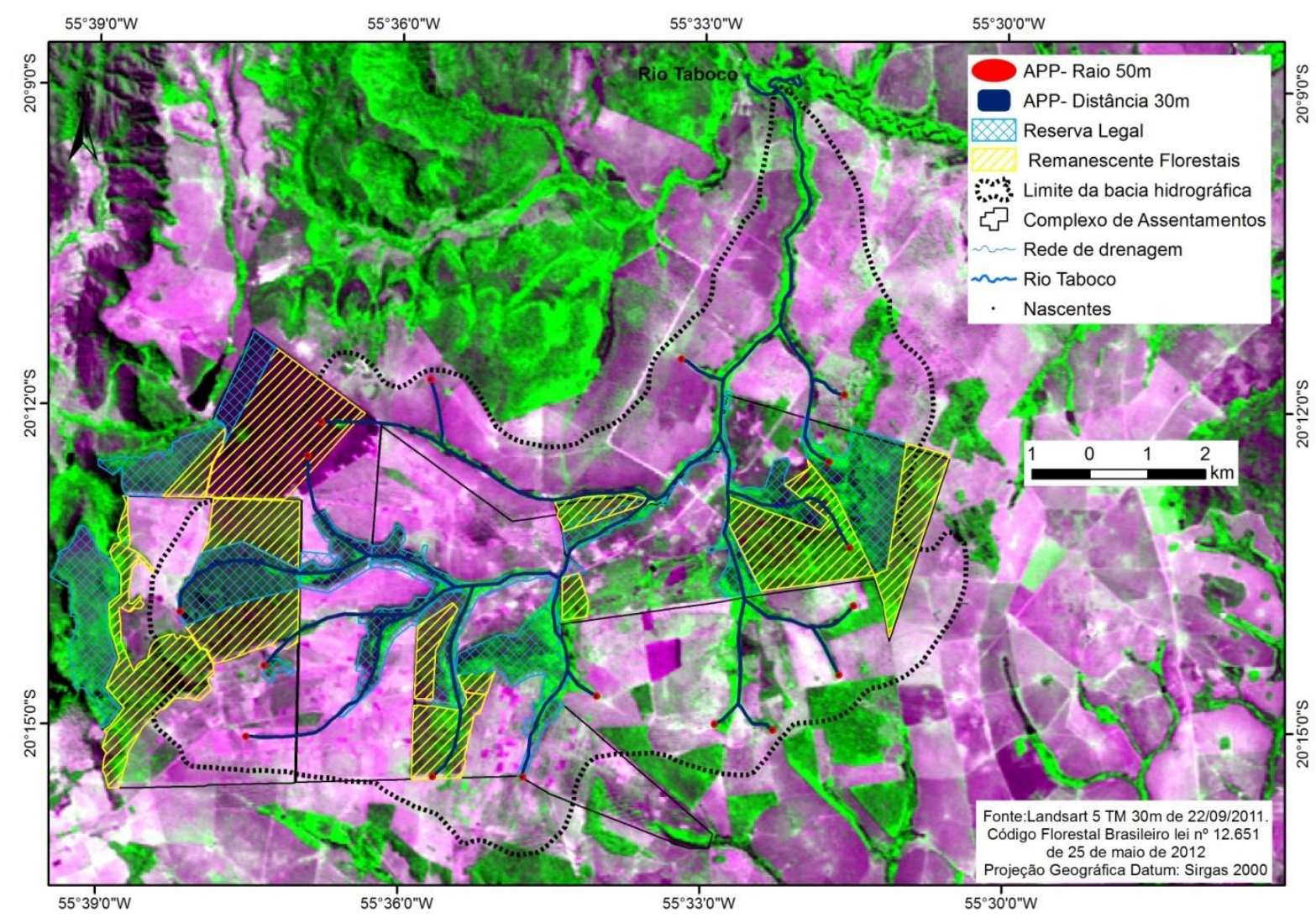

Figura 3- Legislação ambiental da bacia hidrográfica do córrego Indaiá- MS

\section{FRAGILIDADE NATURAL Ȧ EROSÃO E INUNDAÇÃO/ FRAGILIDADE POTENCIAL}

$\mathrm{Na}$ bacia hidrográfica do córrego Indaiá ocorrem três graus (níveis) de fragilidade natural à erosão: A) Baixa, B) Média e C) Alta, conforme pode ser visualizado na figura 4. Os níveis de fragilidade natural à erosão (fragilidade potencial) da bacia hidrográfica do córrego Indaiá estão diretamente associados com suas características pedológicas e geomorfológicas, as quais apresentam predominantemente solos de textura arenosa e as formas de relevo caracterizadas pela presença de colinas convexas, morros e morrote.

A) Fragilidade Baixa: predomina em aproximadamente $21 \%$ da área total da bacia $(20,61$ $\mathrm{Km}^{2}$ ), classe de fragilidade associada com relevo suave ondulado caracterizado pela presença de unidades morfológicas em formas de colinas convexas com inclinações que menores que 
$6 \%$, relacionadas com o desenvolvimento de Latossolos Vermelhos álicos, solos fisicamente e quimicamente frágeis de textura franco-arenosa.

B) Fragilidade Média: encontra-se em sua maioria ao longo da margem esquerda do córrego Indaiá, corresponde a $68,62 \%$ da área de estudo $\left(64,82 \mathrm{Km}^{2}\right)$, ocupa formas de relevo onduladas dominadas por colinas convexas com inclinações entre $6 \%$ a $20 \%$ associadas com solos dominados por arenitos quartzosos de textura arenosa, o mesmo que apresenta como um das suas principais características a baixa capacidade de agregação de partículas e alta susceptibilidade à erosão.

C) Fragilidade Alta: classe com menor representatividade ocupando menos que $0,57 \%$ da área da bacia $\left(0,53 \mathrm{Km}^{2}\right)$, ligada diretamente a relevo fortemente ondulado com inclinações superiores a 30\%, predominado por morro e morrote. Os solos presentes nessa classe são, em sua grande maioria, Neossolos Litólicos denominados de "solo jovem", pois apresentam minerais primários na sua composição, baixa profundidade e baixo grau de intemperização. Essas características determinam um reduzido volume de água e nutrientes disponíveis para as plantas e pequeno volume para o sistema radicular ancorá-las, especialmente árvores que apresentam sistema radicular mais profundo, fatores associados ao relevo fortemente inclinado que favorece o aparecimento de processos erosivos decorrentes de águas das chuvas (OLIVEIRA, 2008). Devido a tais fatores, essas áreas devem ser analisadas com um cuidado especial e/ou destinadas à preservação.

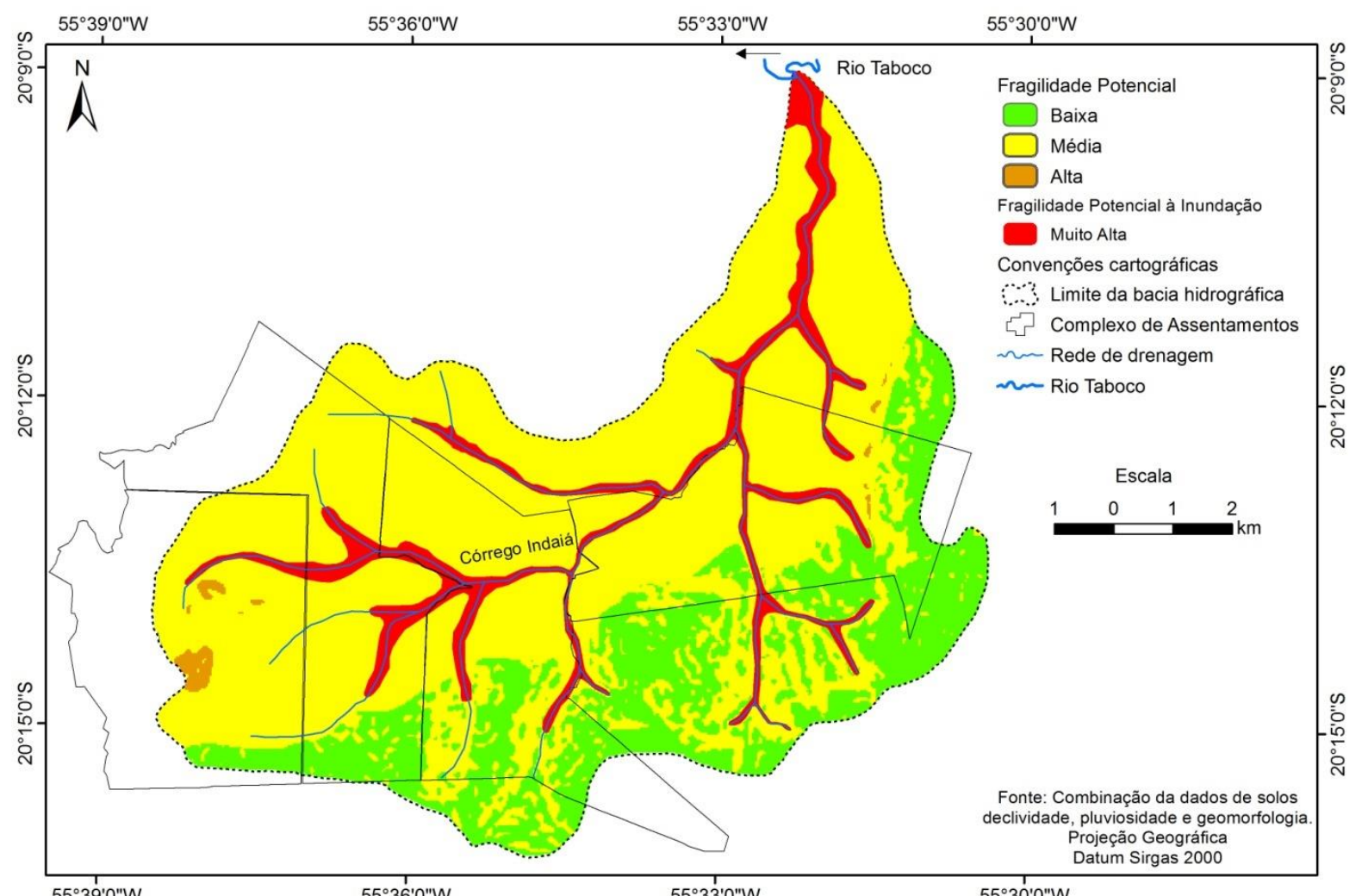

Figura 4 - Fragilidade potencial e potencial natural à inundação da bacia hidrográfica do córrego Indaiá- MS.

No mapeamento foi classificada a área de planície fluvial como de muito alta fragilidade potencial à inundação, que correspondeu a 8,99\% da extensão territorial da unidade hidrográfica $(8,4828$ $\mathrm{Km}^{2}$ ), caracterizada por um relevo plano e solos hidromórficos, associada, em sua maioria, a áreas úmidas. Dependendo do ciclo hidrológico, essa região pode sofrer inundações anuais. Essas áreas 
são definidas, segundo o código florestal brasileiro (BRASIL, 2012), como áreas de preservação permanente (APPs), ou seja, restrita, à ocupação.

\section{FRAGILIDADE AMBIENTAL}

Naturalmente a bacia hidrográfica do córrego Indaiá apresenta características potencialmente frágeis relacionadas principalmente aos solos arenosos e a presença de morros e morrotes de topos convexos, assim a pressão antrópica, exercida pela instalação do complexo de assentamentos, tem influência direta no atual grau fragilidade ambiental da bacia. Pode-se identificar que a bacia hidrográfica do córrego Indaiá possui 4 níveis de fragilidade ambiental: A) Baixa B) Média, C) Alta e D) Muito Alta (Figura 5). A tabela 4 apresenta os graus de fragilidade ambiental da bacia hidrográfica do córrego Indaiá e quantificação de área.

Tabela 4 - Graus (níveis) de fragilidade ambiental e quantificação

\begin{tabular}{|l|l|}
\hline Grau de Fragilidade Ambiental & $\mathrm{Km}^{2}$ \\
Baixa & 4,19 \\
Média & 40,00 \\
\hline Alta & 50,14 \\
\hline Muito Alta & 0,30 \\
\hline Total & 94,63 \\
\hline
\end{tabular}

A) Baixa: corresponde a apenas 4, 44\% da área da bacia, circunscrevem-se as áreas de vegetação natural (Cerradão), que tem um papel fundamental na proteção do solo e estabilização das vertentes, uma vez que essas áreas apresentam solos franco-arenosos que tem como característica a alta fragilidade e formas de relevo suave ondulada (Tabela 5).

B) Média: representa cerca de $42,10 \%$ da área total, associada diretamente com a presença de pastagem, tipo de cobertura vegetal que tem um grau de proteção médio do solo, ocorrem formas de relevo convexas do tipo colinas com declividades até $12 \%$ (média fragilidade) e solos de textura arenosa e franco arenosa. 


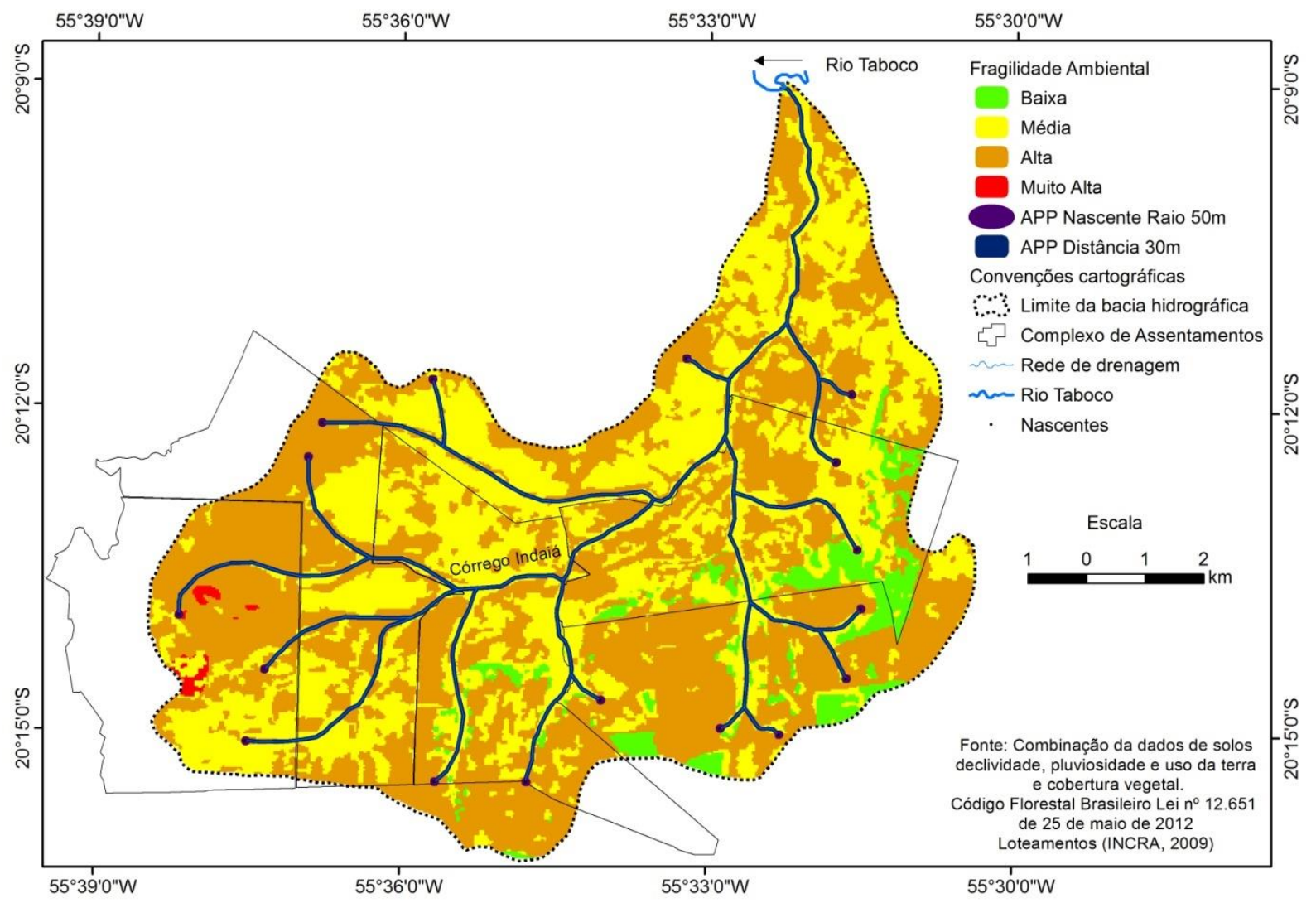

Figura 5 - Fragilidade ambiental da bacia hidrográfica do córrego Indaiá- MS.

C) Alta: apresenta a maior distribuição espacial com aproximadamente $53 \%$ da área de estudo, ocorre ao longo de toda bacia. Estas áreas demonstram alta fragilidade devido a um fator bem definido, a ação antrópica. Constatou-se que as nascentes do córrego Indaiá estão localizadas em áreas de alta fragilidade, fato que implica uma atenção maior para essas áreas de afloramento do lençol freático. Grandes partes das áreas de vegetação natural destinada à preservação foram desmatadas e queimadas, ocasionando a redução da cobertura vegetal, ação que provoca a perda de proteção tanto do solo, quando das nascentes, além das práticas de queimada empobrecerem o solo. Outra classe de uso da terra e cobertura vegetal presente nesse grau de fragilidade é o solo exposto, que tem como sua principal característica a falta de cobertura vegetal, que o torna totalmente vulnerável às ações das chuvas que por consequência originam a uma série de processos erosivos.

D) Muito Alta: ocupa apenas 0,31\% da área da bacia, no entanto, corresponde as áreas com as maiores inclinações (acima de 30\%) e mais elevadas altitudes (380m a 545m), dispostas sobre formas de relevo ondulado (morrote) e fortemente ondulado (morro), ambas associadas à presença de Neossolos Litólicos. A área de morrote possui uma cobertura de vegetação natural (Cerradão) em processo de regeneração devido às queimadas, o que diminui o seu grau de proteção, o morro apresenta uma cobertura de vegetação natural com baixa densidade, característica somada com alta inclinação e tipo de solo arenoso e cascalhento justifica sua altíssima fragilidade.

A partir da análise dos resultados obtidos de fragilidade ambiental da bacia hidrográfica do córrego Indaiá identificou os fatores naturais e antrópicos que influenciaram no seu atual grau de fragilidade ambiental (Quadro 1).

No quadro 1 são apresentadas algumas propostas para o uso ordenado da terra de modo a 
garantir a sustentabilidade econômica dos assentados e pecuaristas, associada com a preservação e conservação dos componentes naturais da bacia de estudo.

Quadro 1 - Graus de fragilidade ambiental, fatores naturais e antrópicos e proposta de uso ordenado da terra

\begin{tabular}{|c|c|c|c|c|}
\hline $\begin{array}{l}\text { Grau de } \\
\text { fragilidade } \\
\text { ambiental }\end{array}$ & Fatores ambientais & Fatores antrópicos & Consequências & $\begin{array}{l}\text { Propostas para } \\
\text { recuperação e utilização } \\
\text { ordenada e sustentável }\end{array}$ \\
\hline Baixa & $\begin{array}{l}\text { Relevo suave } \\
\text { ondulado (inclinações } \\
\text { até } 12 \% \text { ), cobertura } \\
\text { vegetal densa } \\
\text { (cerradão), solos } \\
\text { de textura franco- } \\
\text { arenoso. }\end{array}$ & Não consta. & $\begin{array}{l}\text { Áreas relativamente } \\
\text { protegidas contra ação de } \\
\text { processos de erosivos. }\end{array}$ & $\begin{array}{l}\text { Preservar os } \\
\text { remanescentes florestais } \\
\text { existentes. }\end{array}$ \\
\hline Média & $\begin{array}{l}\text { Relevo suave } \\
\text { ondulado (inclinações } \\
\text { até } 12 \% \text { ), solos } \\
\text { de textura franco- } \\
\text { arenosa e arenosa. }\end{array}$ & $\begin{array}{l}\text { Introdução da pastagem em } \\
\text { áreas de vegetação natural } \\
\text { e manejo inadequado e falta } \\
\text { de planejamento e práticas } \\
\text { conservacionistas. }\end{array}$ & $\begin{array}{l}\text { Áreas de média estabilidade, } \\
\text { todavia as áreas de pastagem } \\
\text { sem o manejo racional estão } \\
\text { susceptíveis a processos } \\
\text { erosivos (ravinas, boçorocas). }\end{array}$ & $\begin{array}{l}\text { Manejar corretamente a } \\
\text { pastagem para evitar o } \\
\text { aumento da degradação. } \\
\text { Analisar o solo, fazer } \\
\text { limpeza, adubação de } \\
\text { manutenção e isolar a } \\
\text { área para a recuperação } \\
\text { do pasto degradado. }\end{array}$ \\
\hline Alta & $\begin{array}{l}\text { Relevo suave } \\
\text { ondulado (inclinações } \\
\text { até } 20 \% \text { ), solos de } \\
\text { textura franco-arenosa } \\
\text { e arenosa. }\end{array}$ & $\begin{array}{l}\text { Desmatamento, queimadas } \\
\text { das áreas de vegetação natural. } \\
\text { Utilização incorreta do solo e uso } \\
\text { inadequado dos recursos hídricos } \\
\text { (captação de água dos córregos } \\
\text { através de pequenas barragens } \\
\text { e represamento de nascentes) } \\
\text { pelos pequenos agricultores do } \\
\text { Complexo de Assentamentos } \\
\text { Indaiá. }\end{array}$ & $\begin{array}{l}\text { Perda e empobrecimento } \\
\text { acelerado do solo (visto que } \\
\text { os solos predominantes } \\
\text { na área apresentam baixa } \\
\text { fertilidade e alta fragilidade } \\
\text { à erosão). Perda de } \\
\text { produtividade. Aparecimento } \\
\text { de erosões, redução de } \\
\text { vazão, qualidade da água e } \\
\text { ampliação dos assoreamentos } \\
\text { no córrego Indaiá e seus } \\
\text { tributários. }\end{array}$ & $\begin{array}{l}\text { Utilizar práticas } \\
\text { conservacionistas } \\
\text { (introduzir culturas de } \\
\text { acordo com a aptidão } \\
\text { agrícola, aplicar o método } \\
\text { de terraceamento, } \\
\text { associado com plantio em } \\
\text { curva de nível). Cercar e } \\
\text { reflorestar as margens } \\
\text { dos córregos e entorno } \\
\text { de nascentes desmatadas } \\
\text { com árvores nativas da } \\
\text { região. }\end{array}$ \\
\hline Muito Alta & $\begin{array}{l}\text { Relevo fortemente } \\
\text { ondulado (inclinações } \\
\text { acima de } 30 \% \text { ) solos } \\
\text { arenosos e cobertura } \\
\text { vegetal de baixa } \\
\text { densidade. }\end{array}$ & $\begin{array}{l}\text { Queimada nas áreas de vegetação } \\
\text { natural. }\end{array}$ & $\begin{array}{l}\text { Surgimento e intensificação } \\
\text { de processos erosivos, } \\
\text { dificultando o livre } \\
\text { desenvolvimento } \\
\text { pedogenético in situ. }\end{array}$ & $\begin{array}{l}\text { Preservar essas áreas, } \\
\text { pois apresentam } \\
\text { características de muito } \\
\text { alta fragilidade ambiental }\end{array}$ \\
\hline
\end{tabular}

\section{CONSIDERAÇÕES FINAIAS}

Sobre a análise da fragilidade ambiental da bacia hidrográfica do córrego Indaiá conclui-se que:

a) A declividade não influenciou diretamente no grau de fragilidade, uma vez que ocorre o predomínio de inclinações inferiores a 6\%;

b) Os solos diferentemente da declividade, apresentaram influência direta no atual grau de fragilidade potencial e ambiental devido aos altos teores de areia em sua composição; 
c) O uso e ocupação da terra da bacia hidrográfica do córrego Indaiá foi modificado intensamente devido à instalação do complexo de assentamentos;

d) A partir espacialização das áreas de proteção verificou-se que as disposições definidas pelo novo Código Florestal Brasileiro não estão sendo cumpridas;

e) A bacia do córrego Indaiá apresenta um predomínio de baixo e médio grau de fragilidade potencial, entretanto quando considerado o fator antrópico tem-se um predomínio de alta fragilidade ambiental, indicando estado de alerta em relação à intensificação da ocupação, sobretudo nas áreas onde se encontram instalados os atuais assentamentos rurais;

f) A utilização das geotecnologias associadas à adaptação metodológica das propostas de análise da fragilidade e vulnerabilidade ambiental permitiu caracterizar os diferentes graus de limitação do ambiente a ocupação, bem como o estabelecimento de propostas para subsidiar ações de planejamento e gestão ambiental na bacia hidrográfica do córrego Indaiá.

\section{REFERÊNCIA BIBLIOGRÁFICA}

AMORIM, R. S. S.; SILVA, D. D.; PRUSKI, F. F.;MATOS, A. T.Influência da declividade do solo e da energia cinética de chuvas simuladas no processo de erosão entre sulcos. Rev. bras. eng. agríc. ambient. [online], vol.5, n.1, pp. 124-130. ISSN 1807-1929. 2001.

BACANI, V. M. Geotecnologias aplicada ao ordenamento físico- territorial da bacia do alto rio Coxim-MS.. 222f. Tese (Doutorado em Geografia Física)- Universidade de São Paulo, São Paulo, 2010. BATISTA, J. P. G., \& da SILVA, F. M. (2013). Avaliação da fragilidade ambiental na microbacia do riacho Cajazeiras no semiárido Potiguar. Boletim Goiano de Geografia,33(1), 53-72, 2013

BERTONI, J.; LOMBARDI NETO, F. Conservação do Solo. São Paulo. Ícone. P.355, 2008.

BRASIL, Ministério das Minas e Energias. Secretaria Geral. Projeto RADAMBRASIL: Geologia, Geomorfologia, Pedologia, Vegetação e Uso potencial da terra.,. Folha SE. 21. Campo Grande. Rio de Janeiro, 1982. BRASIL. Código Florestal Brasileiro. Lei 12.651, de 25 de maio de 2012. Brasília, Diário Oficial da União, 2012.

BRASIL. Plano de conservação da bacia do alto Paraguai: Análise Integrada e Prognóstico da Bacia do Alto Paraguai. Brasília: PNMA, 1997.

CÂMARA, G.; SOUZA, R. C. M.; FREITAS, U. M.; GARRIDO, J. C. P. SPRING: Integrating Remote Sensingand GIS with Object-Oriented Data Modelling. Computers and Graphics, v. 20, n. 3, p. 395-403, May-Jun 1996.

CÂMARA, G.; MONTEIRO, A. M. V.; MEDEIROS, J. S. Fundamentos epistemológicos da ciência da geoinformação. In: CÂMARA, G.; DAVIS, C.; MONTEIRO, A. M. V. (Orgs). Introdução à ciência da geoinformação. Disponível em: <http://www.dpi.inpe.br/gilberto/livro/introd>. Acesso em: 21, maio, 2012.

CUNHA, E. R.;BACANI, V. M.; FACINCANI, E. M.; SAKAMOTO, A. Y.; LUCHIARI, A. Remote sensing and GIS applied to geomorphological mapping of the watershed stream Indaia, MS, Brazil. In: 8th IAG International Conference on Geomorphology, 2013, Paris-France. 8th IAG International Conference on Geomorphology, 2013.

CREPANI, E.; MEDEIROS, J. S.; HERNANDEZ FILHO, P.; FLORENZANO, T. G.; DUARTE, V.; BARBOSA, C. C. F. Sensoriamento remoto e geoprocessamento aplicados ao Zoneamento Ecológico-Econômico e ao ordenamento territorial. (INPE-8454-RPQ/722). Instituto Nacional de Pesquisas Espaciais, São José dos Campos. 2001.

DIRETORIA DO SERVIÇO GEOGRÁFICO (DSG) - Folha SF 21-X-A-III. Aquidauana. Escala 1:100.000. Primeira impressão, 1972.

FITZ, Paulo Roberto. Cartografia Básica. São Paulo: Oficina de Textos, 2008.

FLORENZANO, T. G. Geomorfologia: conceitos e tecnologias atuais. São Paulo: Oficina de Textos, 2008. 
GARZOTTI, A. A degradação do meio ambiente na agricultura de cana-de-açúcar. 2007. Revista Educação Ambiental. Disponível em < http://www.revistaea.org/artigo.php?idartigo=519\&class=21 $>$ Acesso 20 março 2013.

INCRA, Instituto Nacional de Colonização e Reforma Agrária. Disponível em < http://www.incra.gov.br/ index.php/noticias-sala-de-imprensa/noticias/9946-incra-lanca-complexo-de-assentamentos-em-aquidauana $>$ Acesso, 21, março, 2013.

COGO, N. P; LEVIEN, R; SCHWARZ, R. A. Perdas de solo e água por erosão hídrica influenciada por métodos de preparo, classes de declive e níveis de fertilidade do solo. Revista Brasileira de Ciência do Solo, Viçosa, v. 27, n. 4, p. 743 - 753, 2003.

KAGEYAMA, P. Y. Estudo para implantação de matas de galeria na bacia hidrográfica do Passa Cinco visando a utilização para abastecimento público. Piracicaba: Universidade de São Paulo,. Relatório de Pesquisa.1986.

LIMA, W. P. Função da mata ciliar. In: SIMPÓSIO SOBRE MATA CILIAR, 1.,1989, Campinas. Anais... Campinas: Fundação Cargil, P.25-42. 1989.

MACEDO, M. C. M. Degradação de pastagens: conceitos, alternativas e métodos de recuperação. In: Curso de pastagens, Embrapa Gado de Corte, 12p. 2001.

NOVO, E. M. L. M. Sensoriamento Remoto. Princípios e Aplicações. São Paulo: Edgard Blucher Ltda, 2010. OLIVEIRA, J. B. Pedologia Aplicada. $3^{\text {a }}$ Ed. FEALQ, Piracicaba. 2008. 545p.

PETSCH, C.; MONTEIRO, J. B.; DAL SANTO, T. Análise da importância do fator declividade para elaboração de cartas de fragilidade ambiental. In: $9^{\mathbf{0}}$ SINAGEO - Simpósio Nacional de Geomorfologia. Rio De Janeiro / RJ, 2012.

PINTO, A. L. Saneamento básico e suas implicações na qualidade das águas subterrâneas da cidade de Anastácio (MS). 1998 175. Tese (Doutorado em Geociências)- Universidade Estadual Paulista/ Instituto de Geociências e Ciências Exatas, Rio Claro, 1998.

ROSS, J. L. S. Análise Empírica da Fragilidade dos Ambientes Naturais e Antropizados. Revista do Departamento de Geografia, nº 8. FFLCH.SP. São Paulo, 1994.

SANT'ANNA NETO, J. L. O Caráter Transicional do Clima e a Diversidade da Paisagem Natural na Região de Aquidauana. In: II Semana de Estudos Geográficos: Desenvolvimentos e Geografia, Aquidauana. Anais... UFMS/CEUA, v.1, p.188-128, 1993.

SANTOS, R, D.: Manual de descrição e coleta de solo no campo, R.D. dos Santos e outros autores. $5^{\mathrm{a}}$ ed. Revista e ampliada Viçosa, Sociedade Brasileira de Ciência de Solo, 2005.

SCOPEL, I; SOUZA, M. S; MARTINS, A. P. I. Infiltração de água e potencial de uso de solos muito arenosos nos cerrados (savanas) do Brasil. Boletim Goiano de Geografia, v. 33, n. 2, p. 203-219, 2013.

SILVA, V. R. Análise sócio-ambiental da bacia do rio Biguaçu-SC: subsídios ao planejamento e ordenamento territorial.2007. 227f. Tese (Doutorado em Geografia Física)- Universidade de São Paulo, São Paulo.

SPÖRL, C. Metodologia para elaboração de modelos de fragilidade ambiental utilizando redes neurais-MS. 2007. 185f. Tese (Doutorado em Geografia Física)- Universidade de São Paulo, São Paulo.

VALERIANO, M. M. TOPODATA: guia de utilização de dados geomorfométricos locais - São José dos Campos: INPE, 2008.

VILLELA, S.M.; MATTOS, A. Hidrologia aplicada. São Paulo: McGRAWHill do Brasil, 1975. 245p.

Trabalho enviado em janeiro de 2015

Trabalho aceito em fevereiro de 2015 